\title{
Study on Reconstruction Techniques of the Nipple-Areola Complex
}

\author{
SILVIU ADRIAN MARINESCUㄹ, CATALIN GHEORGHE BEJINARIU1*, ANDREEA BADEANA", SABINA TANASESCU-CIUVICA², \\ DAN MIRCEA ENESCU ${ }^{3}$ \\ ${ }^{1}$ Bagdasar-Arseni Emergency Clinical Hospital, Department of Plastic and Reconstructive Surgery, 12 Berceni Road, 041915, \\ Bucharest, Romania \\ ${ }^{2}$ Bagdasar-Arseni Emergency Clinical Hospital, Department of Anaesthesia and Intensive Care,12 Berceni Road, 041915, Bucharest, \\ Romania \\ ${ }^{3}$ Grigore Alexandrescu Emergency Clinical Hospital, Department of Plastic and Reconstructive Surgery, 30-32 lancu de Hunedoara \\ Blvd, 011743, Bucharest, Romania
}

\begin{abstract}
Increasing the incidence of breast cancer worldwide is an alarming factor for the medical community and also an additional reason for accountability. Oncological treatment, followed by subsequent reconstructive stages, are traumatic events that without a doubt exert their adverse effects on the quality of life of these patients. The reconstruction of the nipple-areola complex represents the final element in the treatment of patients who have suffered from breast cancer and must follow basic principles such as: reproducibility, efficacy, short duration of treatment and low rate of complications. The present material presents the various surgical techniques dedicated to the reconstruction of the nipple-areola complex, presenting their advantages and disadvantages based on a 5-year study. The use of single-stage techniques associated with medical tattooing were the main factor in increasing the satisfaction of the patients included in the research.
\end{abstract}

Keywords: breast reconstruction, medical tattoo, areola pigmentation, mastectomy

The issue of breast reconstruction in patients who have undergone radical or partial mastectomy is an element of topical interest within the internaional scientific community. Different views on the optimal moment of reconstruction, the chosen reconstructive technique, and the postoperative therapeutic behavior still raise multiple questions, the opinions on the ideal treatment technique being divided [1]. Without a doubt the reconstruction of the nipple-areola complex is a niche topic and in the last years it transforms into a real overspecialization for the plastic surgeon, being an extremely extensive field in terms of the used reconstruction techniques, the chosen treatment options and the development of the chemical substances (pigments) that can be a significant advantage in transforming these reconstruction techniques [2, 3].

The promotion of singular surgical techniques, which solves the whole range of particularities of the treated case, is applied without any hesitation in regard to the reconfiguration of the nipple-areola complex [4]. In the recent years the literature has been abounding with materials dedicated to reducing the total duration of reconstructive treatment by performing all surgical procedures during the same intervention. Therefore, terms such as nipple sparing, medical tattoo, unconventional breast tattoo, C-V flap technique are more and more common in the context of single-stage nipple-areolar reconstruction $[5,6]$. The desire to maximally reduce the time the patient is exposed to risks associated with the surgery including anesthesia, as well as to maintain the patients' degree of satisfaction at the highest level are elements that have contributed to the rapid development of the new reconstruction techniques dedicated to the nipple-areola complex $[7,8]$.

The main objectives of the nipple-areola complex reconstruction are to obtain a color and texture as close as possible to the contralateral areola in the case of unilateral mastectomy, or to respect the tone of the skin in case of bilateral mastectomy. Without a doubt the diameter, position, shape and projection of the nipple-areola complex are elements that contribute equally to the achievement of a good postoperative result $[9,10]$. The above mentioned objectives can be accomplished by using various surgical techniques consisting of local flaps, cartilage grafts, fullthickness skin grafts, medical tattooing, or a combination thereof [11]. The technique used depends equally on the local peculiarities of the case, as well as on the experience of the plastic surgeon regarding the reconstructive protocols [12]. The general attitude in the recent years is to perform all the necessary reconstructive techniques during the same operation. The use of local anesthesia has also become a necessity, given the desire to reduce the risks associated with surgery, as well as to achieve a high degree of patient satisfaction. Improving the satisfaction of the patients is the main argument behind merging all the surgical procedures into a complex reconstructive intervention. According to specialized literature, the two-stage (classical) reconstruction of the nipple-areola complex is associated with a low degree of patient satisfaction, mainly due to the long duration of the reconstructive treatment; this is probably due to the fact that the patients are at the end of the treatment period and have already gone through major surgery such as mastectomy and subsequent breast reconstruction. It is therefore easy to understand why performing the nipple projection and the areola reconstruction in different stages significantly reduces the satisfaction of the patients. The ideal protocol for the reconstruction of the nipple-areola complex is performed in a single surgical procedure that is effective, reproducible and has a low rate of postoperative complications [13]. These particularities contribute equally to achieving a high degree of patient satisfaction.

The introduction of medical tattooing techniques in the reconstruction protocol of the nipple-areola complex contributes to a significant reduction of the hospitalization for these patients. The onset of the single - stage reconstruction surgery overlaps with the accelerated development of medical tattooing techniques. Skin grafting plasties are practically no longer necessary by using

*email: drbejinariu@gmail.com 
different classes of pigments in order to create the areola. The advantages of this technique are numerous, the reduced degree of complexity, the absence of the donor area and the shortened hospitalization are just a few of these elements [14, 15]. Sasaki and Matsumine have published in 2018 an interesting article dedicated to the development of the medical tattooing reconstruction protocol [16]. In the study the authors have managed to improve the reconstruction results by introducing 4 changes to the classical tattooing techniques: blurring the edges of the areola, creating the illusion of an irregular appearance, modifying the position for symmetry, and creating a shadow effect [17].

Rigorous documentation involves understanding the advantages and disadvantages of the various existing reconstruction techniques [18]. The main drawbacks of medical tattooing are the lack of studies dedicated to understanding the effects of injecting various pigments into the dermis [19]. In their article in 2018 Minghettia et al. show that there is no supranational regulation in the European Union regarding the use of these pigments [20]. The molecular effects exerted by these chemicals are still incompletely elucidated and require additional studies for their understanding. Although there is plenty of material devoted to understanding the effects of bacterial contamination related to different pigments and the associated repercussions, nanotoxicity seems to be a topic neglected by the internaional scientific community [21]. However, the history of tattoo techniques stretches for a few centuries, being part of the lifestyle of many communities at internaional level and notbeing associated with major life threatening illnesses. Another interesting feature is the one published in 2015 by Ashok Ghorpade about the association between tattoo and psoriazis [22]. The author presents the onset of the disease after performing a ceremonial tattoo, but further studies are needed in order to understand the mechanism of appearance and to highlight a cause-effect relationship. Without a doubt the onset of psoriazis may be triggered during the reconstruction of the areola using medical tattooing, so that the therapeutic options should be reconsidered for patients presenting this risk [23].

The emoional healing of patients who have undergone oncological treatment and then reconstructive surgery can also be achieved by less conventional techniques [24,25]. Temporary tattooing has proven to be an effective technique for some patients in order to increase postprocedural satisfaction as evidenced by the material published by Osborn and Cohen in 2017 [26]. Therefore, there are patients who could benefit from temporary medical tattoos and a possible periodical adjustment in order to achieve emoional balance [27].

There are numerous morphological problems that gravitate around the reconstruction of the nipple-areola complex, starting from simple shape and contour changes to the integration of tissue grafts, resorption of the used pigments, and cell turnover rate as a predictor of long-term outcome. Therefore, understanding these complex biological processes requires rigorous documentation and applied studies on all procedures included in the reconstructive protocol.

\section{Experimental part}

\section{Materials and methods}

The present material is based on the statistical analysis carried out by the authors over 5 years, including 52 patients enrolled in the National Breast Reconstruction Program developed in the Plastic Surgery Department of the
"Bagdasar - Arseni" Emergency Clinical Hospital and from the medical activity performed by them in the Perfect Aesthetic private clinic. The following variables were monitored for the statistical analysis: the time span from the reconstruction of the breast to the reconstruction of the nipple-areola complex, the types of procedures and techniques, the duration of the surgical intervention, the diameter of the reconstructed areola, the patients' degree of satisfaction, the option for repeating the procedure, and the complication rate depending on the type of reconstruction [28].

For medical tattooing the authors used an approved device, the disposable cartridges used varying depending on the targeted area. A circular set with 5 needles was used for the outline of the areola, the central area being covered by the using 4-needle linear cartridges. The pigments used during the intervention were those recommended by the tattoo device manufacturer, using standard shades, as well as combinations of these in order to obtain the desired tones.

Table 1

COMPOSITION OF MEDICAL TATTOO INKS

\begin{tabular}{|c|l|c|}
\hline No. crt. & \multicolumn{1}{|c|}{ Substance } & Concentration* \\
\cline { 1 - 3 } $\mathbf{1}$ & Mercury & \multirow{2}{*}{$\mu \mathrm{kg}-\mathrm{mg} / \mathrm{kg}$} \\
\hline $\mathbf{2}$ & Cadmium salts & \\
\hline $\mathbf{3}$ & Oxides of chromium and cobalt & \\
\hline $\mathbf{4}$ & Titanium & $180.9 \mathrm{~g} / \mathrm{kg}$ \\
\hline $\mathbf{5}$ & Copper & $31.3 \mathrm{~g} / \mathrm{kg}$ \\
\hline $\mathbf{6}$ & Aluminium & $5.9 \mathrm{~g} / \mathrm{kg}$ \\
\hline
\end{tabular}

Medical tattooing requires approximately $1 \mathrm{mg}$ of ink injected per $\mathrm{cm}^{2}$ of tattoo. The composition of the used inks usually involves almost insoluble pigments dispersed in water, additives such as formulants, dispersants, and preservatives and sometimes fragrances. The concentration of the main substances contained in commercial inks are presented in table $1[29,30]$. Organic colourants are currently used in the majority of the tattoo inks. Analyses of commercial inks presented in the specialized literature show that modern colourants usually contain titanium, barium, aluminium [31] and copper, while antimony, arsenic, cadmium, chromium, [32] cobalt, lead, and nickel are considered contaminants and have been reduced or replaced $[33,34]$. The collected data was processed by establishing the average values for each parameter in order to highlight possible correlations between the type and technique used, the rate of associated complications, as well as the effect they exert on the patients' degree of satisfaction.

\section{Results and discussions}

From the 52 patients included in the study, 36.53\% (19 patients) have benefited from medical tattooing for the reconstruction of the nipple-areola complex, the average duration of the procedure being 39 minutes (table 2). The association between medical tattooing and C-V flap was observed in $25 \%$ ( 13 patients) of the cases, the average time needed for the reconstruction being $53 \mathrm{~min}$. For the reconstruction of the nipple-areola complex 8 patients have chosen plasties with areolar grafts from the contralateral areola, the average duration of the surgery being $51 \mathrm{~min}$ (fig. 1.

The association between the areolar graft with nipple reconstruction using C-V flap was requested by $23.07 \%$ of the patients, the average time required to perform the procedure being $55.20 \mathrm{~min}$.

Regarding the requested type of procedure $67.30 \%$ of the patients opted for the single-stage nipple-areola 


\begin{tabular}{|c|c|c|c|c|c|c|}
\hline Reconstruction type & $\begin{array}{l}\text { Total no. of } \\
\text { interventions }\end{array}$ & Protocol type & $\begin{array}{c}\text { No. of interventions/ } \\
\text { Type }\end{array}$ & $\begin{array}{l}\text { Duration of } \\
\text { procedure } \\
\text { (minutes) }\end{array}$ & $\begin{array}{c}\text { Degree of } \\
\text { satisfaction }\end{array}$ & \\
\hline Medical tattooing & 19 & $\begin{array}{c}\text { Single Stage } \\
-{ }^{-}-{ }^{2} \text { Stage }\end{array}$ & $\overline{2}^{--}$ & $\begin{array}{r}39 \\
- \\
-39\end{array}$ & $\begin{array}{c}9 \\
--\end{array}$ & Table 2 \\
\hline $\begin{array}{l}\text { Medical tattooing + } \\
\text { C-V Flap }\end{array}$ & 13 & $\begin{array}{l}\text { - Single Stage } \\
-\overline{\text { Two Stage }} \\
- \text { Single }\end{array}$ & $\overline{7}$ & 54 & $-\overline{9}-$ & $\begin{array}{l}\text { NIPPLE-AREOLA } \\
\text { COMPLEX } \\
\text { TECHNIQUESUSED } \\
\text { IN THE STUDY }\end{array}$ \\
\hline Areolar Graft + C-V Flap & 12 & $\begin{array}{l}\text { Single Stage } \\
-\overline{\text { Two Stage }}-\overline{-}\end{array}$ & & 54 & $-\frac{9}{8}-$ & \\
\hline & & - Single Stage & $\overline{8}$ & $51^{-}$ & $\overline{9}$ & \\
\hline Areolar graft & 8 & $-\overline{\text { Two Stage }}-\overline{-}$ & & & & \\
\hline
\end{tabular}

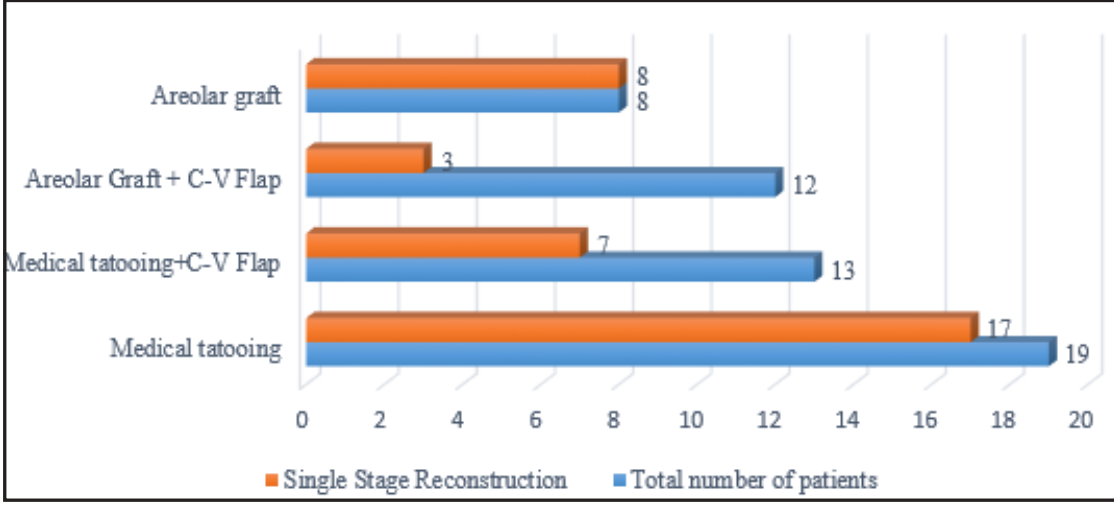

Fig. 1 Classification by surgical procedure and protocol

complex reconstruction technique and $32.69 \%$ for reconstruction in 2 stages. The average time span between breast reconstruction and nipple-areola complex was about 5.86 months.

The average diameter of the reconstructed areolas was $4.72 \mathrm{~cm}$, the contracture of the postoperative wounds being the main factor that contributed to the reduction of this parameter below the target value of $5 \mathrm{~cm}$ (fig. 2).

Postoperatory complications were noted in $8.57 \%$ of patients who received single-stage reconstruction, the frequency of complications being much higher for patients who opted for two-stages reconstruction (29.41\%).

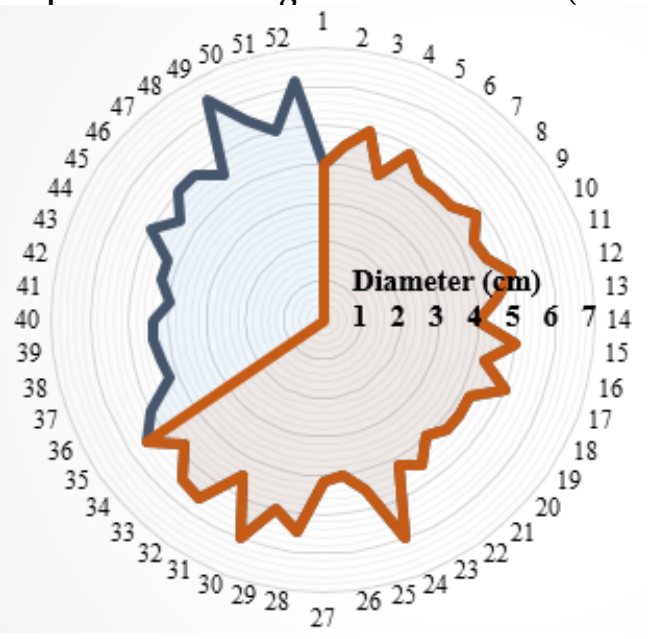

-Two Stage Reconstruction -Single Stage Reconstruction
The satisfaction degree of the patients that underwent single-stage reconstruction was 8.94 on a scale of 1 to 10 (fig. 3), while patients with two-stage reconstruction had a lower level of satisfaction (7.29) (fig. 4). The majority of the patients who benefited from single-stage reconstruction (94.28\%) and $64.70 \%$ of the patients that underwent two-stages reconstruction have opted for repeating the procedure considering its course (repeat option).

The nipple-areola complex reconstruction is a topical subject, the improvement of the treatment protocol

\section{Fig. 2 Diameter of the reconstructed areola for \\ the 52 researched cases}

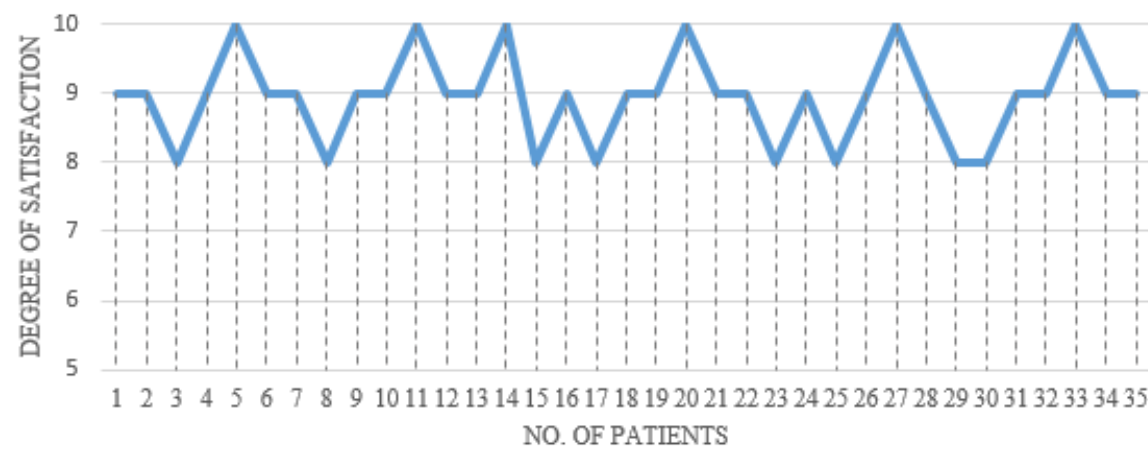

Fig. 3 Degree of satisfaction for the patients that have undergone single-stage reconstruction 


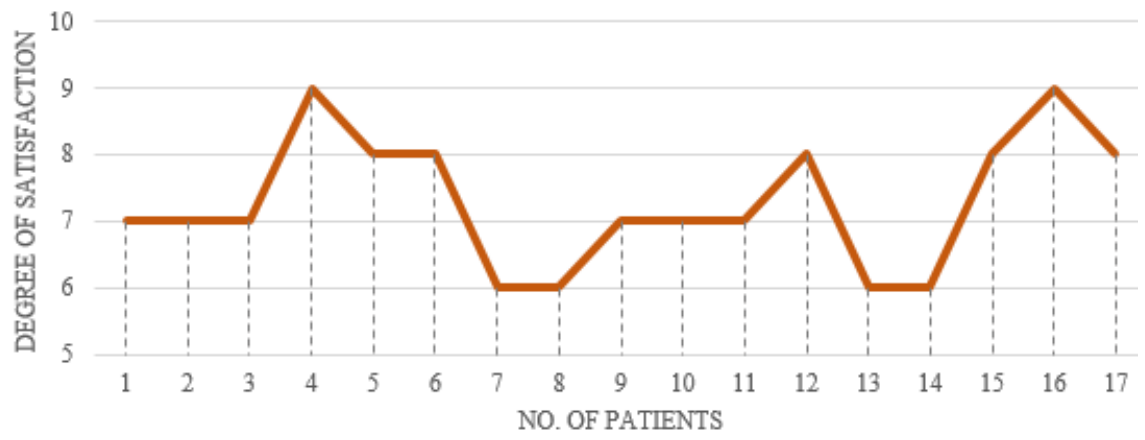

Fig. 4 Degree of satisfaction for the patients that have undergone double-stage reconstruction

representing the main theme of debate dedicated to this subject in the international scientific community. The development of modern reconstruction techniques in a single surgical stage, the reduction of the treatment time, the reduction of the risks associated with anesthesia, and the decrease of complications are the main objectives for the development of the reconstruction protocol. As evidenced by the patients, reconstruction of the nippleareola complex performed in two surgical stages show the main disadvantage of prolonged duration. Considering the particularities of the oncological and reconstructive treatment that these patients have undergone, it is easy to understand why shortening the duration of the treatment is an extremely important criterion in increasing the satisfaction of these patients.

The development of medical tattooing techniques has led to good results from both the patient's and the surgeon's point of view. Respecting the main aesthetic elements with relative ease, such as local topography, color tone and symmetry with respect to the contralateral areola were the main advantages of using these techniques. The use of controlled-origin pigments, approved tattooing devices and the experience of the medical staff also constitute important elements for achieving a good post-operative result. Considering that $61.53 \%$ of the patients included in the study opted for the reconstruction including medical tattooing (simple or in combination with other surgical techniques), it can be concluded that at least within the studied group the minimal invasiveness associated with tattooing techniques was a major criterion in deciding on the adopted surgical technique. Regarding the patients' options related to the reconstructive technique, the high percentage of medical tattoos can be justified by the fact that the 3D technique generates very good aesthetic results. By using shadows and different tones of pigments, the image of a natural nipple can be achieved without the surgical trauma associated with the classical reconstruction. The drawback of the technique is that reconstruction using medical tattooing does not provide any benefits related to the projection of the nipple-areola complex.

Post-treatment follow-up for medical tattooing is much easier than in case of reconstruction with areolar or cartilage graft, the patient respecting the strict local hygiene guidelines up to 14 days after the procedure, the surgeon not being required to perform any examination during that period. Reconstructions with areolar tissue grafts, cartilage grafts and local flaps require specialized postoperative monitoring in order to quickly identify possible complications. The complications associated with the reconstructive protocol performed in two stages were largely represented by delayed healing, infection and dehiscence. The increased frequency of complications within the studied group can also be attributed to the double surgical risk caused by the existence of two surgical interventions, the presence of the donor zones and the low compliance of the patient determined by the increased duration treatment.

Without a doubt no matter the quality of the chosen pigment, its particularities with respect to its durability and the used technique, it is necessary to repeat the procedure after a variable period of time; but this was not a discouraging factor in this study. The over time blurring and fading of the pigments was even interpreted as an encouraging factor in the long-term for these patients, and eventual differences in tone were thus more easily compensated with the passage of time.

\section{Conclusions}

The statistical analysis presented in this paper presents the advantages of the reconstruction techniques of the nipple-areola complex by using medical tattooing (simple or in combination with other surgical techniques) to the classical techniques used up to now. Increasing the satisfaction of patients represents a very important objective in the reconstruction of the nipple-areola complex, being achieved in the present study by adopting single-stage reconstruction techniques associated with medical tattooing. Reproducibility, effectiveness, reduced duration of treatment, low rate of complications, and a shortened learning curve for reconstructive procedures are all elements that support the use of these techniques in order to achieve good and lasting results and to increase the satisfaction of patients benefiting from this treatment.

Without a doubt, further studies are needed in order to analyze the advantages and disadvantages of different surgical techniques in the plastic surgeon's portfolio, and the widening of the database is certainly an important element for increasing their statistical significance. International literature abounds with statistical data on the advantages and disadvantages of different reconstruction techniques, but this is not the case of national literature. Therefore, the development of scientific materials using the National Breast Reconstruction Program as starting point brings an important contribution for the development of the Romanian medical community.

\section{References}

1. MIYAKE R., KINOSHITA S., SHIMADA N., UCHIDA K., TAKEYAMA H., MORIKAWA T., Surgery Today, 48, nr. 6, 2018, p. 591.

2. LILIAV B., SCOTT J., Springer, Cham, 2018, p. 675.

3. CHA H.G., KWON J.G., KIM E.K., Aesthetic Plastic Surgery, 43, nr. 1, 2019, p. 76.

4. KOMIYA T., ITO N., IMAI R., ITOH M., NAITO M., MATSUBAYASHI J., MATSUMURA H., Aesthetic Plastic Surgery, 39, nr. 2, 2015, p. 209.

5. ROBINSON E.C., KANG V., MCNAB A.B., ANTONY A.K., Springer, 2017, p. 651.

6. KIM H., PARK S.J ., WOO K.J., BANG S.I., Aesthetic Plastic Surgery, 2019, p. 1.

7. SIMONACCI F., BERTOZZI N., PESCE M., SANTI P.L., RAPOSIO E., Open Medicine J ournal, nr. 5, 2018, p. 84. 
8. GOUGOUTAS A.J., SAID H.K., UM G., CHAPIN A., MATHES D.W., Plastic and Reconstructive Surgery, 141, nr. 3, 2018, p. 404.

9. NIMBORIBOONPORN A., CHUTHAPISITH S., Gland Surgery, 3, nr. 1, 2014, p. 35-42.

10. LEWIN R., AMOROSO M., PLATE N., TROGEN C., SELVAGGI G., Aesthetic Plastic Surgery, 40, nr. 5, 2016, p. 724.

11. BITIK O., UZUN H., Aesthetic Plastic Surgery, 40, nr. 5, 2016, p. 690. 12. BEJINARIU, C.G., MARINESCU, S.A., ENESCU, M.D., Modern Medicine, 26(1), 2019, p. 17.

13. ISLAM P.S., CHANG C., SELMI C., GENERALI E., HUNTLEY A., TEUBER S.S., GERSHWIN M.E., Clinical Reviews in Allergy \& Immunology, 50, nr. 2, 2016, p. 273.

14. DE CUYPER C., DUBELLOY R., Springer-Verlag Berlin Heidelberg, 2018, p. 121.

15. SISTI A., GRIMALDI L., TASSINARI J., CUOMO R., FORTEZZA L., BOCCHIOTTI M.A., ROVIELLO F., D'ANIELLO C., NISI G., Eur J Surg Oncol, 42, nr. 4, 2016, p. 441.

16. SASAKI Y., MATSUMINE H., Plastic Reconstructive Surgery Global Open, 6, nr. 6, 2018, p. 1.

17. TOMITA S., MORI K., MIYAWAKI T., Aesthetic Plastic Surgery, 42, nr. 3, 2015, p. 656.

18. CHA H.G., KWON J.G., KIM E.K., Aesthetic Plastic Surgery, 2018, p. 1.

19. ISAACST., NGWANYA R.M., LEHLOENYA R.J ., South African Medical Journal, 108, nr. 9, 2018, p. 714.

20. MINGHETTIA P., MUSAZZIA U.M., DORATI R., ROCCO P., Science of The Total Environment, 651, 2018, p. 634.

21. ADIS MEDICAL WRITERS, Drugs \& Therapy Perspectives, 34, nr. 9 , 2018, p. 425.

22. GHORPADE A., International J ournal of Dermatology, 54, 2015, p. 1180. -21
23. ADIS MEDICAL WRITERS, Drugs \& Therapy Perspectives, 2015, p. 277.

24. KASTEN E., Journal fur Asthetische Chirurgie, 2017, p. 114.

25. AUGUSTINE P., RAMESH S.A., NAIR R.K., SUKUMARAN R., JOSE R.,

CHERIAN K., MURALEE M., AHAMAD I., Indian Journal of Surgical Oncology, 2018, 9, nr. 3, p. 343.

26. OSBORN L.P., COHEN P.R., Clinics in Dermatology, 36, nr. 3, 2018, p. 426.

27. NAGURA-INOMATA N., IWAHIRA Y., HAYASHI N., KOMIYA T., TAKAHASHI 0., SpringerPlus, 5, 2016, p. 579.

28. BEJ INARIU, C.G., MARINESCU, S., GIUGLEA C., Romanian Medical Journal, LXVI(1), 2019, p. 33.

29. LAUX P., TRALAU T., TENTSCHERT J., BLUME A., AL DAHOUK S., BAUMLER W., BERNSTEIN E., BOCCA B., ALIMONTI A., COLEBROOK H., DE CUYPER C., DAHNE L., HAURI U., HOWARD P.C., JANSSEN P., KATZ L., KLITZMAN B., KLUGER N., KRUTAK L., PLATZEK T., SCOTTLANG V., SERUP J., TEUBNER W., SCHREIVER I., WILKNIß E., LUCH A., Lancet, 387, 2016, p. 395.

30. MANSO M., PESSANHA S., GUERRA M., REINHOLZ U., AFONSO C., RADTKE M., LOURENCO H., CARVALHO M., BUZANICH A., Biological Trace Element Research, p. 596.

31. DRAGNEA D., GUDOVAN D., ZAHARIA E., BILDEA C.S., Rev.Chim.(Bucharest), 69, no. 12, 2018, p. 3353.

32. MITIU M.A., MARCUS M.I., VLAD M., BALACEANU C.M., Rev.Chim.(Bucharest), 69, no. 3, 2018, p. 571.

33. FORTE G., PETRUCCI F., CRISTAUDO A., BOCCA B., Sci Total Environ, 407, nr. 23, 2009, p. 5997.

34. FORTE G., PETRUCCI F., CRISTAUDO A., BOCCA B., Open Chem. Biomed. Meth. J., 2, 2009, p. 42.

35. BEJ INARIU, C.G., APOSTOLESCU, I., MARINESCU, S., Romanian J ournal of Medical Practice, 14 (1), 2019, p. 48.

$\overline{\text { Manuscript received: } 12.10 .2018}$ 